\title{
Current Concepts and Translational Uses of Platelet Rich Plasma Biotechnology
}

\author{
I. Andia, E. Rubio-Azpeitia, J.I. Martin and M. Abate \\ Additional information is available at the end of the chapter \\ http://dx.doi.org/10.5772/59954
}

\section{Introduction}

A two-decade long research has expedited knowledge about tissue repair mechanisms, and the field of Regenerative Medicine is gaining ground stimulated by novel insights and the development of therapeutic biotechnologies, intending to restore tissue architecture and functionality. Regenerative Medicine technologies concern not only traumatic tissue injuries but also involve the biological manipulation of pathological conditions aiming to drive tissue circumstances to normal, i.e. the recovery of tissue homeostasis.

Recent advances in biology and the new understanding of mechanisms such as angiogenesis, inflammation and main cell activities including proliferation, differentiation and metabolism have prompted researchers to seek how to manipulate these aspects of tissue and cell biology. Translation of this knowledge into the development of regenerative medicine technologies is imperative in order to address the current health care demand markedly boosted by demographic changes. Indeed the dramatic increase in the economic and social burden of chronic and degenerative diseases urges the development of novel therapies.

Biological interventions in Regenerative Medicine fall into four main categories including gene therapy, tissue engineering, cell-based therapies, and platelet rich plasma (PRP) therapies, with different success in clinical translation. For example, tissue engineering approaches, i.e. cells loaded within scaffolds, are in development but still several limitations of 3D tissue constructs are unresolved; these questions include biocompatibility, improvements in mechanical properties and/or the size of the 3D constructs [1]. Similarly, the efficacy of different categories of cell therapies, including mesenchymal stem cells, embryonic stem cells or induced pluripotent stem cells (iPSC), is being tested [2]. However, while registration of new clinical trials using MSCs derived from the bone marrow or from adipose tissue is growing rapidly supported by both public and private investments, the iPSC therapies are advancing at a slower 
pace because reprogramming raises serious concerns about safety because of their genetic instability and potential to form tumors.

$\mathrm{PRP}$, an autologous plasma fraction of peripheral blood, is the simplest regenerative medicine intervention that is rapidly extending to multiple medical fields mainly due to the easy use and biosafety that facilitates translation in humans. In fact, regulatory requirements for cell therapy involve multiple preclinical experiments to demonstrate their safety and nonteratogen effects in addition to GLP compliance in the preparation, and the use of adequate expensive installations [3]. In contrast, PRP therapies involve minimal manipulation, and in general, regulatory requirements are easy to comply thereby facilitating the widespread clinical use and commercial success of PRP kits and devices. In fact, PRP can be prepared by using any of the commercial systems available. PRPs can also be prepared by in house procedures, providing that basic rules of quality are implemented.

While regenerative medicine with cells is directed to inherent non-healing problems and a wide range of pathological conditions, PRP embrace normal healing conditions such as tissue repair during surgical invasion or traumatic injuries seeking to enhance and accelerate physiological repair. Alternatively, PRPs as occurs with cell therapies, seek to direct nonhealing conditions, e.g. chronic conditions such as osteoarthritis (OA) or tendinopathy, towards healing and restoration of tissue homeostasis.

Due to the biosafety of these products, i.e. advantageous balance risk-benefit, clinical applications have preceded the basic research. Actually, in its very beginnings PRPs have been used with a vague idea of the biological mechanisms they were influencing. Thereafter, most studies were directed to examining clinical outcomes rather than identifying the precise biochemical mechanisms underlying PRP effects, which remain to be elucidated in the most part. In fact, PRP widespread use was not driven by the principles of the scientific methods instead patient demand has been boosted by sports news and propaganda reporting that outstanding elite athletes had been successfully treated with PRP. The need is clear, to investigate and describe main PRP targets and action mechanisms underlying their clinical effects. In fact, translational medicine addresses both, the biological and the clinical aspect of the novel biotechnologies.

In this book chapter, first, we will discuss recent progress on understanding the tissue regeneration process with a particular focus on the healing stages, and the role of PRP released signaling proteins in targeting different cells and inducing paracrine actions. Current biological interventions aiming tissue regeneration stem from two concepts, namely cells responsible for tissue homeostasis, and the signaling cytokines that control cell fate. Several cell phenotypes are involved in tissue repair and some processes such as inflammation and angiogenesis are commonly involved in the repair process in several conditions. Hence, several notions of tissue repair mechanisms are compatible with the biological hallmarks of regeneration in different tissues. Common mechanisms involved in healing can be modulated using PRP. This is the basic knowledge to drive clinical applications.

Second, from a practical point of view on PRP biotechnology we will discuss the main formulations, and summarize commercial systems to prepare PRP. Regulatory requirements will be briefly exposed. 
Lastly, we will focus on translational uses, that is to say current PRP interventions from the clinical investigation perspective. We will summarize PRP applications in surgery with special emphasis in novel developments, the current use of PRP in ulcers, ophthalmology and dermatology, as well as foremost conservative treatments in orthopedics and sports medicine.

We will discuss main obstacles for the advancement of PRP science and future perspectives.

\section{Tissue repair and regeneration}

Despite growing knowledge on tissue regeneration mechanisms currently we are incapable to fully regenerate human tissues. The only approximation to tissue regeneration in the human body is the so-called "compensatory regeneration" in the liver. In fact, after lobe removal the liver compensates the loss and recovers its former size by balanced proliferation of all the existing cell types, including hepatocytes, kupffer macrophages, endothelial cells, duct cells, and fat storing cells. Moreover, these cells retain their functional identity and are able to produce all the liver-specific enzymes necessary for liver function [4].

In contrast to the lack of regenerative mechanisms in humans where there is no return to the embryonic state and no recapitulation of differentiating mechanisms, some amphibians as the salamander, after amputation replace their body parts by recapitulating embryological events. In these amphibians regeneration involves reactivation of developmental mechanisms in the post-natal life to restore wounded tissues identically as they were before injury.

Research in this area of experimental biology has provided useful information to the field of Regenerative Medicine. For example, the study of amphibians offers important insights into the mechanisms involved in the regeneration of complex structures. Indeed, after limb amputation in the salamander, a mass of undifferentiated cells called blastema is formed, and the blastema is capable of growing into different body parts [5].

Nevertheless, dramatic differences between frogs and salamanders in tissue repair/regeneration exist. Indeed adult frogs, despite being amphibians, cannot recapitulate embryologic mechanisms in their adult life. These differences are mainly attributed to at least three broad dissimilarities, first in their immune systems, secondly in cell differentiation mechanisms, and lastly in their potential for nerve regeneration [6].

Therefore these three notions derived from studies on experimental biology will drive our exposition of potential layers of PRP control in healing mechanisms. We will focus firstly, on immune-modulatory mechanisms i.e. the pattern of leukocyte infiltration (PMNs, monocytes, lymphocytes), and macrophage polarization, second the importance of stem/progenitor cell activation, and adequate differentiation, and third the requirement of nerve participation, as regeneration is dependent on the presence of nerves. In fact a minimum number of nerve fibers is necessary for regeneration to take place. We will emphasize the importance of an adequate crosstalk between immune cells, progenitor cells as well as local differentiated cells and the paracrine actions. 
All these regenerative events constitute different layers of biological control that can be influenced by PRP administration.

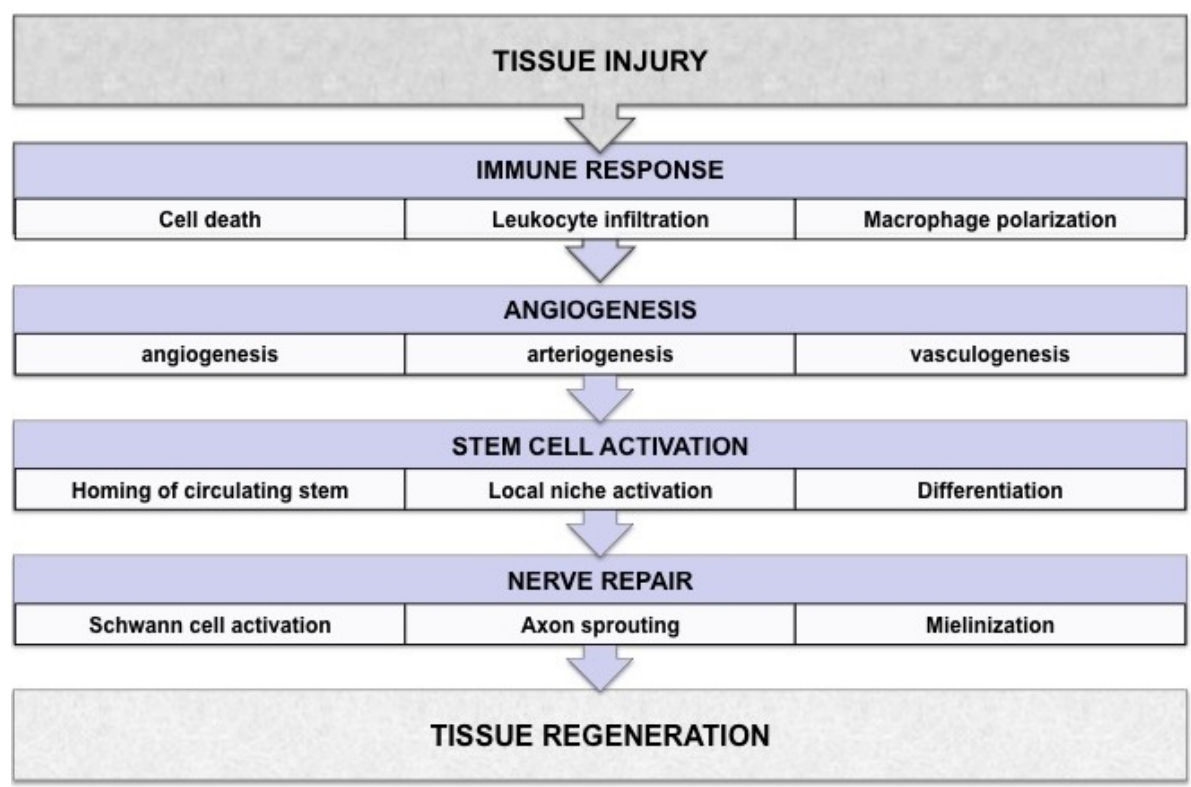

Figure 1. Potential layers for PRP influence in tissue regeneration

\section{Outlook for the control of tissue healing using PRP}

\subsection{Inflammation}

\subsubsection{Cell death and DAMPs in the extracellular space}

Injury in multicellular organisms is accompanied by cell damage and death, proportional to the magnitude of tissue injury that triggers a sophisticated sequence of reactions to cope with the insult. The degree of the inflammatory response depends on the severity of the injury that can induce different magnitudes of cell damage and death. Loss of cell integrity activates innate immune sensors by releasing to the extracellular space a myriad of intra-cytoplasmic molecules, known as DAMPs (Danger Activating Molecular Patterns). Among the DAMPs released by dying cells there is a growing list including cytosolic and nuclear proteins such as high mobility group box 1 (HMGB1), alarmins such as S100, and non-proteins including uric acid, DNA, RNA, and ATP. The inflammatory response triggered by the detection of DAMPs is an evolutionary conserved mechanism present in both vertebrates and invertebrates. 
DAMPs transmit stress signals to the organism, and stimulate innate immune responses, starting by leukocyte infiltration, following by macrophage polarization and closing with the resolution of inflammation. This set of mechanisms is known as the inflammatory response, and serves to minimize the insult, and repair the damaged tissue in doing so contributes to the recovery of tissue homeostasis.

Cell death can result from injury but can also occur physiologically as a component of tissue homeostasis, since all tissues in accordance with their physiologic turnover rate replace old cells by new ones. In tissue turnover cell death is not accompanied by any inflammatory reaction, probably because DAMPs in the extracellular space do not reach a threshold concentration. Importantly, errors in the control of immune homeostasis may be behind chronic diseases.

The administration of PRP during this phase can rescue damaged cells as PRP contains cytokines that can promote cell survival, as shown both in vivo and in vitro. For example, during cell auto-transplantation for the treatment of tissue defects in plastic surgery, the use of PRP increases the survival of pre-adipocytes and adipocytes. Pre-adipocytes treated with PRP showed anti-apoptotic activities and decreased the expression of molecular mediators of cell death including Bcl-2-interacting mediator of cell death [7]. Additionally PRP can protect human tenocytes against cell death induced by ciprofloxacin and dexamethasone [8]. Furthermore, PRP could alleviate BMSC death under hostile conditions increasing the levels of paracrine interactions via stimulation of PDGFR/PI K/AKT/NF-kB signaling pathway [9]. PRP also promoted rejuvenation of aged and senescent MSC in vitro [10].

TLR receptors and DAMP-TLR activation is thought to be important in restoring homeostasis after cell death. Recent research has added layers of complexity to our understanding of PRP, and information about how molecular components of PRP interfere with DAMP signaling through NF-kb illustrates the anti-inflammatory effect of PRP in several tissues [11].

\subsubsection{Pattern of leukocyte infiltration}

The magnitude, pattern and timing of leukocyte infiltration are better described when tissue stress is induced by pathogens. However, in the case of sterile injuries, the extravasation of leukocytes in response to tissue damage is less understood. Actually, it is uncertain how PRP influences these three parameters: first, the magnitude of leukocyte infiltration, second, the pattern, and lastly, the timing.

The way PRP influences infiltrating immune cells is important because the latter play a major role in determining the outcome of tissue repair along with the secretory phenotype of local cells

\subsubsection{Polimorphonuclear cell (PMNs) infiltration}

The increase in vessel permeability and chemotactic signals from the injured tissues facilitates extravasation and movement of leukocytes within tissues by diapedesis. The use of PRP in this stage of healing modifies several aspects, first PRP increases vessel permeability by releasing 


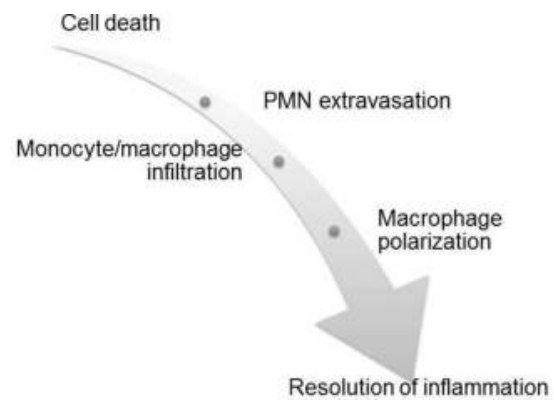

VEGF (also known as permeability factor, PF); in addition catecholamines such as dopamine and noradrenaline are delivered from dense granules in addition to histamine, all with synergistic effects in augmenting vessel permeability [12].

Polymorphonuclear cell (PMNs), including neutrophils (60-65\% of the total leukocytes), eosinophils and basophils extravasate from the blood stream and perform a graded infiltration that reaches maximums in 12-24 h and is followed by decline, stop and apoptose. Excessive PMNs infiltration may be detrimental for the tissue because PMNs release a wide array of cytotoxic molecules. Granule components include several non-selective proteolytic enzymes, cytotoxins, antimicrobial peptides; in addition to the production of reactive oxygen species (ROS). The lifespan of neutrophils in the bloodstream is limited to hours but when they extravasate, the presence of DAMPs' agonists in the infiltrated tissues prolongs neutrophil survival.

PRP may influence both the amount of neutrophil infiltration and the survival of neutrophils in the injured tissues. In fact, PRP delivers both CCL and CXCL chemokines that attract different leukocyte subsets. In particular, CXCL7 (very abundant in platelets) in collaboration with NAP2 provides a strong chemotactic signal for neutrophil infiltration. In addition, PRP releases a known chemotactic cytokine for neutrophils, CXCL8/IL8. Moreover, we have recently shown that these chemotactic signals are reinforced and augmented by local cell synthesis in vitro [13]. PRP can also modify the lifespan of infiltrated leukocytes by modifying the molecular environment of the injury.

Thus, the administration of PRP would presumably modify the innate immune response, mainly by altering the molecular environment and the chemotactic driven pattern of neutrophil infiltration, the intensity and the timing. However, these effects may be dependent on the tissue conditions and anatomical location.

\subsubsection{Monocyte/macrophage infiltration and polarization}

During the initial days subsequent to injury (from $2 \mathrm{~h}$ to $72 \mathrm{~h}$ ) monocyte/macrophages gradually infiltrate the tissue, ready to clean up apoptotic neutrophils. Indeed, macrophages are specialized in clearance of death cells.

The expression "macrophage polarization" refers to the ability of macrophages to change their functional phenotype in response to molecular signals they sense in their microenvironment. 
Macrophages have been categorized conventionally into pro-inflammatory M1 and tissue repairing M2 phenotypes. In the presence of LPS or IFN-gamma macrophages are "classically" polarized and denominated M1 macrophages. They have an inflammatory phenotype as they express IL-1b, IL-6, IL-8 and TNF-a.

Instead, in the presence of high levels of IL-4, M2 macrophages are "alternatively" polarized and they produce anti-inflammatory cytokines, including IL-10, IL-1Ra, CD-36, scavenger receptor A or mannose receptor. However, growing knowledge about macrophage plasticity indicates that M1/M2 polarization is an over-simplified view. As a matter of fact, a continuum range of polarization states exist between the two extremes M1 and M2.

Inflammatory mechanisms are protective mechanisms that should be ideally self-limited and lead to complete resolution returning to tissue homeostasis. Recent data indicate that M1/M2 activation states are extremely plastic to external signals and macrophages can be repolarized from M2 to M1 states although the mechanism is unknown [14]. Resolution of inflammation is an active process involving the biosynthesis of specialized pro-resolving mediators by M2 polarized macrophages.

Assuming that manipulation of macrophage polarization can be a tool for therapeutic exploitation, it is imperative to gain knowledge about how PRP influences macrophages. In fact, PRP modifies the environment and macrophages can gain distinct functions supporting their participation in inflammation or alternatively in the resolution of inflammation. Previous data showed that CXCL4/PF4 induces a polarization state distinct from M1 or M2 [15], and the term M4 polarization has been proposed. This is relevant because PF4 is one of the most abundant cytokines stored in platelets' alpha-granules (micromolar concentrations), and is released from platelets upon activation. However, M4 polarization has been studied in the context of atherosclerosis, but not in tissue repair.

Therefore, further research is indispensable to establish how PRP would influence the activation state of macrophages, and whether resolution of inflammation can be achieved by exposing macrophages to determined molecular environments.

\subsubsection{Regulation of fibrotic pathways}

Fibrotic tissue is characterized by excessive type 1 collagen accumulation that hinders tissue regeneration. The presence of myofibroblasts is central to fibrotic tissue production. They originate from a spectrum of cellular sources, and several molecular pathways can induce the transition of cells to myofibroblasts. In fact, myofibroblasts can describe a functional status rather than a fixed cell phenotype. Fibrosis is predominantly controlled by TGF-b1, which is secreted as an inactive protein associated to a latent protein. TGF-b1 enhances strongly the synthesis of type 1 collagen by creating an autocrine loop; additionally it is an antiapoptotic agent for myofibroblasts. TGF-b1 is abundant in PRP, stored in considerable amounts in agranules and secreted upon platelet activation. Additionally leukocytes secrete TGF-b1. TGFbeta-stimulated M2-like macrophages have profibrotic activity [16]. Instead, serum amyloid protein present in plasma has been shown to inhibit fibrosis in different models by regulating macrophage function. Thus, PRP actions are theoretically paradoxical regarding the develop- 
ment of fibrosis. However, clinical practitioners using PRP injections rarely report the presence of fibrosis.

Scarring is also a key problem for axon regeneration because fibrotic tissue may block axon growth and impair axon function.

\subsection{Angiogenesis}

The supply of oxygen is essential for cell metabolism and wound healing. Indeed, poor tissue perfusion creates a hypoxic environment that impairs the healing process. Angiogenesis involves multiple biological mechanisms including cell migration, proliferation, and differentiation.

Vascularization occurs through outgrowth of preexisting blood vessels (angiogenesis) and involves cell migration and proliferation. Upon injury, vessels consisting of naked endothelial cell channels have potential to sprout and branch providing nutrients and oxygen to regenerating tissues. Vessel sprouting and enlargement are driven by migratory endothelial cells (EC) called tip cells. Additional types of cells, i.e. smooth muscle cells and pericytes, are involved in vessel stabilization. Both mechanisms, angiogenesis and arteriogenesis, involve a wide array of cytokines and growth factors that can be supplied in physiological concentrations by PRP administration (Table 1). Essentially, PRP cause endothelial cell proliferation and capillary tube formation in vitro.

Alternatively to angiogenesis, new vessels can be formed through mobilization and domiciliation of progenitors of endothelial cells to sites of tissue injury (vasculogenesis) or ischemic tissues, a process mediated by VEGF and SDF-1a binding to CXCR4 receptors on EPCs.

PRP augments ischemic neovascularization presumably due to the stimulation of the three above described mechanisms: angiogenesis, arteriogenesis and vasculogenesis. Arteriogenesis is the main driver of restoration of blood perfusion in ischemia [17].

Indeed, the importance of coagulation factors and of platelet secretome (VEGF, TGF-b1, PDGF, bFGF, angiopoietin) is evident for angiogenesis, not only because of their individual actions but because of beneficial synergies between these GFs. For example, Ang-1, an EC survival factor, stimulates capillary tube formation synergistically with VEGF. Also synergy between both PDGF and VEGF results in the formation of a more mature vascular network than when each factor is given alone [18]. Also the angiopoietin system contributes to vessel maintenance growth and stabilization.

Paradoxically, platelets also provide several antiangiogenic factors necessary for vessel downregulation. Angiogenesis inhibitors (CXCR3 agonists) such as PF4 and TSP-1 are very abundantly stored in platelets. Additionally, angiostatin, a product of plasminogen proteolysis, inhibits angiogenesis. Both pro- and anti-angiogenic properties have been attributed to TGFb1. At low doses it contributes to the angiogenic switch in part by upregulation of VEGF and uPA, whilst at high doses contributes to the resolution of angiogenesis by inhibiting EC proliferation and migration, promoting the reformation of the basement membrane. 


\begin{tabular}{|c|c|}
\hline PRP- associated angiogenesis stimulators & PRP-associated angiogenesis inhibitors \\
\hline Vascular endothelial growth factor (VEGF) & Angiostatin \\
\hline Basic fibroblast growth factor (bFGF) & Endostatin \\
\hline Platelet-derived growth factor (PDGF) & Platelet factor 4 (PF4) \\
\hline Epidermal growth factor (EGF) & Plasminogen activator inhibitor (PAI-1) \\
\hline Hepatocyte growth factor (HGF) & Transforming growth factor (TGF-beta) \\
\hline Insulin like growth factor 1, 2 (IGF-1, IGF-2) & Thrombospondin-1 (TSP-1) \\
\hline Angiopoietin (ANGPT1) & Tissue inhibitor of metalloproteinases $-1,-4$ \\
\hline Matriz metalloproteinases 2, 9 (MMP-2 and -9) & (TIMP-1,-2,-3,-4) \\
\hline Lipoprotein A (LPA) & Fibronectin \\
\hline Sphingosine-1-phosphate (SIP) & $\alpha 2$-macroglobulin \\
\hline \multicolumn{2}{|l|}{ Stromal cell derived factor (SDF-1, CXCL12) } \\
\hline \multicolumn{2}{|l|}{ Heparanase } \\
\hline \multicolumn{2}{|l|}{ Deoxyribose-1-phosphate } \\
\hline \multicolumn{2}{|l|}{ CD40-L } \\
\hline \multicolumn{2}{|l|}{ IL-8, CXCL8 } \\
\hline \multicolumn{2}{|l|}{ CXCL12 } \\
\hline Down-regulate vessel permeability & Increase vessel permeability \\
\hline Angiopoietin-1 & VEGF \\
\hline Serotonin & Histamine \\
\hline \multirow[t]{2}{*}{ Sphingosin-1-P } & Noradrenaline (NE) \\
\hline & Dopamine (DA) \\
\hline
\end{tabular}

Table 1. PRP-associated positive and negative regulators of angiogenesis. Some of these molecules may have both proand anti-angiogenic potential depending on the situation at the time of their release and/or the expression of cryptic sites. Reproduced from International Journal of Clinical Rheumatology, August 2012, Vol.7, No4, Pages 397-412 with permission of Future Medicine Ltd.[21]

As shown above, PRP provides the opportunity to therapeutically manipulate angiogenesis by targeting multiple cell phenotypes. Crosstalk between cell types along with multiple signals constitutes the complex system that regulates angiogenesis. Not only the activities of endothelial cells, but also of endothelial progenitors, smooth muscle cells and pericytes are influenced by PRP signals. Pericytes, crucial for vessel stabilization, can arise from different cell sources since they can transdifferentiate from the endothelium, a common vascular progenitor or a mesenchymal progenitor. The association of pericytes with newly formed vessels regulates EC proliferation, survival, migration, differentiation and vascular branching, blood flow and vascular permeability. Pericytes have important roles in tissue repair. For example, in skeletal muscle perycites arise from blood vessels and express NG2 proteoglycan and alkaline phosphatase and they efficiently regenerate the muscle expressing myogenic markers only when fully differentiated [19-20]. However, no information is yet available about the interaction of the molecular pool released from PRP and pericytes.

Other cooperative mechanisms such as partial degradation of the ECM and basement membrane are necessary to facilitate cell migration during angiogenesis. Actually, several protease 
families released from PRP including plasminogen activators (uPA and PAI-1), and MMPs have been characterized as having a role in the proteolytic degradation and remodeling of the subendothelial basement membrane and the surrounding ECM. By digesting ECM proteins, these enzymes create a path for tip cell migration. Platelets contain fibrinolytic factors and enzymes that may regulate precisely the pericellular proteolytic environment required for the control of cell migration and matrix remodeling. For example urokinase plasminogen (uPA) and plasminogen activator inhibitor type I (PAI-1) proceed as modifiers of the pathway that impact migratory events. Almost all cell types need to migrate under physiological or pathological conditions. Clearly the binding of PAI-1 with its several targets has the potential to influence the motile program at multiple levels. Further complexity is provided by the presence of endogenous proteases inhibitors (TIMPs) that control the activity of proteases.

\subsection{Stem/precursor cell activation and differentiation}

It has been demonstrated in last years that most organs have a resident pool of somatic, tissue specific cells. These stem cells are located in niches characterized by a typical spatial localization, the anchorage of stem cells to supporting cells, and the presence of typical extracellular matrix. These cells are docked in specific microenvironments that control their survival and self-renewal capabilities preventing them from exhaustion. In the niche, the integration of stimulatory and inhibitory signals determines cell quiescence.

In general, these cells are mitotically quiescent. PRP contains agents able to restore mitosis in quiescent precursor cells, consequently mitotically arrested cells are able to divide again. By definition, these precursor stem cells are capable of self-renewal and have various potentialities for differentiation. In general they are committed to differentiate in the local cell phenotype and are designed to substitute dying cells during turnover, trauma or pathology. PRP participates in mobilization of progenitor cells and proliferation but its effects in differentiation are controversial [22].

PRP influences the number of stem cells by virtue of its mitotic effect and maintains stemness in most settings. Actually, the effects of PRP on the differentiation of synovium derived MSCs are negative in all three lineages and PRP alone maintains MSCs stemness [23]. Besides PRP inhibits differentiation of adult rat tendon stem cells towards nontenocyte lineage [24]. Recent research in skeletal muscle repair has shown that PRP maintains stemness of muscle progenitor cells [25]. Though, PRP did not interfere with the osteogenic, chondrogenic and myogenic differentiation in the appropriate differentiation conditions.

In many cases of traumatic injury or disease the quantity and potency of this endogenous pool of precursor cells is insufficient to regenerate compromised tissues and migration and homing of mesenchymal stem cells circulating in the blood stream is required.

In fact, bone marrow contains several types of stem cells including hematopoietic cells that differentiate into mature blood cells, endothelial progenitor cells and MSCs which are proposed to give rise to the majority of marrow stromal cell lineages including chondrocytes, osteoblasts, fibroblasts, adipocytes, endothelial cells. Circulating MSCs in the blood stream 
can home injured tissue in response to chemoattractants released from platelets such as SDF-1a/CXCL12.

PRP was shown to be effective in promoting the migration of MSCs. In addition PRP can increase the number of MSC by stimulating proliferation. Actually the number of CMOs manufacturing cells for in-human trials are taking advantage of the mitogen properties and fetal calf serum [FCS) the typical cell culture supplement is being substituted by PRP. Several studies showed that population cell doublings is enhanced by PRP, that is to say PRP reduces the time needed to get a predefined cell number necessary for efficacious cell therapy [26].

\subsection{Modulation of nerve repair}

\section{Peripheral nerve injury and regeneration}

Peripheral nerves have the capacity to regenerate after an axonal injury. There are several kinds of peripheral nerve damages depending on the damage of the axon and surrounding tissue. After an injury or a breakdown, axon is able to regrow expressing repair-related molecules and aided by Schwann cell activation, proliferation, phagocytic activity and production of neurotrophic factors. These factors activate signaling cascades promoting synthesis of molecules related to axonal regeneration events. In addition to producing bioactive molecules, Schwann cells form structures called Bünger bands, which have as a function the physical guidance of growing axons [27]. They also recruit macrophages to the injury site to remove debris from the injury and help them supporting axon repair by secreting chemokines. As a result, axon healing is the result of the interaction between molecular signals and cellular events which allow proper growth of the axonal stump and consequent recovery of its functional activity at the end of healing process.

Peripheral nerve fibers are stimulated immediately after injury and release several neuropeptides into the microenvironment of the wound. Substance $\mathrm{P}$, neuropeptide $\mathrm{Y}$ and calcitonin gene-related peptide (CGRP) influence endothelial cells, fibroblasts and are involved in vasoregulation and angiogenesis.

\section{Growth factor and cytokine involvement in nerve healing}

All these results have been attributed to growth factors released from platelets when activation occurs, but an accurate function and optimal concentration have not been identified [28]. Platelets release a high number of growth factors which may have precise effects on their own, or work synergistically depending on their concentration. Wound healing is influenced by diverse growth factors secreted by platelet such as PDGF, TGF- $\beta$, PF4, VEFG, EGF, PDEGF, IGF-I and others. Although these are not classically classified as neurotrophic, they have been demonstrated to have a role in Schwann cell migration, proliferation, neuron metabolism, synthesis of neurotrophic factors, matrix formation and myelinization and thus in axon regeneration [29-33]. Also, platelets release other molecules which are not growth factors such as catecholamines, histamine, serotonin, ADP, ATP and others which take part in blood vessel formation, immune reactions both innate and adaptive, and thus in tissue regeneration [30]. 
Nerve healing depends on equilibrium between Schwann cell proliferation and activation and neurotrophic molecules which create a regenerative milieu which helps axon repair and myelinization. Several growth factors present in PRP, such as PDGF, TGF- $\beta 1$ and FGF-II, have shown to promote Schwann cell proliferation, activation and differentiation which may explain beneficial PRP effects shown in the previously commented studies [30,33]. These growth factors, for which Schwann cells and neurons have membrane receptors, trigger the expression and subsequent synthesis of classic neurotrophic factors such as nerve growth factor [NGF), Glial derived growth factor (GDNF), brain-derived neurotrophic factor (BDNF) and ciliary neurotrophic factor (CTNF)[30, 32]. Also, PDGF expression has been shown to be enhanced in neurons after a nerve injury, which may support the theory that this growth factor has an important role in axon healing. Another growth factor present in PRP, which has been signaled as neurotrophic is VEGF. It has been shown to be neuroprotective, to also augment Schwann cell proliferation and axon growth [30]. IGF-I has also been pointed out as a central promoter of nerve healing. In vitro, it has been observed that IGF enhanced neuron axonal growth and that myelinization does not occur when IGF is removed. Also, IGF has been shown to promote Schwann cell proliferation and migration. In vivo, IGF injections in the site of nerve injury have been proved to ameliorate nerve healing and myelinization [28, 29,30, 31].

In the clinical arena, perineural injections of PRP induced sensorial recovery in leprosy peripheral neuropathy [34].

\section{PRP formulations and regulatory requirements}

Innovative therapeutic tools appear in the horizon when basic knowledge and research surpasses a certain threshold and is ready for translation into the clinics. PRP technologies showed up in the late 80s, mainly based on increased knowledge about the functional role of platelets. Platelets are cytoplasmic fragments of the megakaryocyte in the bone marrow. A variety of molecules are stored in platelets' granules either synthesized by their parent cell the megakaryocyte or captured in the circulation. In PRP technologies platelets are used because of their capability to function as vehicles for growth factors and cytokine delivery.

Initially platelets were mainly studied because of their fundamental role in hemostasia. Allogeneic PRP, either derived from a single donor or pooled donors, has been used since the $60 \mathrm{~s}$ as a transfusion product. In fact platelet transfusion is indicated in patients with platelet counts below $30,000 \mathrm{plt} / \mathrm{ul}$ or below $100,000 \mathrm{plt} / \mathrm{ul}$ if they are to follow a surgical procedure. Later in the 80 s clinical researchers showed off that beyond their role in hemostasia, PRP derived product (PDWH) were effective in the management of chronic leg ulcers [35] and were an aid in cardiac surgery [36].

In the 90s, maxillofacial surgeons and oral implantologists introduced the clinical use of PRPs as autologous modifications of fibrin glue. They were confounded by the effects of PRP in bone regeneration in doing so accelerating the stability of dental implants. Of note, the antiinflammatory properties in soft tissues, presumably attributed to the presence of platelets in the preparation, was another hallmark in PRP findings. 
In the new millennium, the use of PRP has been boosted not only by research in maxillofacial surgery and oral dentistry but also by new applications in orthopedics and sports medicine. In 2007, the term and definition of platelet rich plasma was introduce in Pubmed as a medical subject heading $(\mathrm{MeSH})$ to be used for indexing scientific articles.

However, the definition of PRP in Pubmed is out of date by several reasons. First, PRP is not only used in surgical procedures but it is also used in the conservative management of nonhealing ulcers and as an injectable in the management of chronic pathologies such as tendinopathies or osteoarthritis. Secondly, the current definition claims that GFs in platelets enhance tissue regeneration this is true but only up to a point. In fact, not only GFs from platelets but also plasmatic GFs have a crucial role in repair. Besides, this definition overlooks the hundreds of proteins released from platelets that also participate in healing. Despite all these limitations, PRP inclusion as MeSH term has served to harbor PRP research under a unique term.

PRPs differ from conventionally synthesized drugs in that they are products derived from living sources. Indeed platelets are lively cells and they may experiment several temporary transformations from preparation to local tissue delivery. The process is known as platelet activation and involves changes in platelet morphology, aggregation, centralization of granules, and secretion of their content to the extracellular milieu. Another peculiarity is that PRP products are complex multi-molecular mixtures that cannot be readily characterized and reproducibility in the composition is influenced by biological inter-individual variability.

\subsection{Types of PRP products}

PRP is prepared by taking a given volume of blood from a patient and processing it to separate blood components and concentrate the platelets and optionally the leukocytes. Importantly, the manipulation of blood in order to obtain PRP is minimal.

The nomenclature of PRP products reached a zenith of confusion at the beginning of the new millennium. In fact, more names than products appeared and the number of commercial terms was endless, including platelet concentrates (PC), autologous growth factors (AGF), plasma rich in growth factors (PRGF), platelet gel (PG), platelet rich fibrin matrix (PRFM) etc... It was evident that there were more names than PRPs to be named.

In 2009, Dohan [37] inspired the present nomenclature and classification of PRPs. Broadly speaking PRPs were categorized as pure PRP and leukocyte and platelet rich plasmas. Considering fibrin architecture and platelet counts we can differentiate further PRP subsets. Different PRP devices and harvest yield in terms of platelet and leukocyte count lead to the proposal of classification systems for PRP.

Alternatively to commercial automatic systems, PRP can be prepared in blood banks with highly standardized procedures. In this setting, PRP is prepared from a higher volume of blood, quality is assessed and aliquots of PRP are frozen for posterior applications. PRP obtained in blood banks are less expensive than PRPs obtained with automatic devices. 
For blood withdrawal, many PRP protocols use anticoagulants to prevent blood from clotting. Most kits use ACDA or sodium citrate to chelate calcium ions in doing so preventing prothrombin conversion into thrombin. Other anticoagulants (i.e. heparin, EDTA) are avoided because they may compromise platelet stability and activation. Notwithstanding, ACDA and sodium citrate make the plasma acidic and some protocols recommend buffering the PRP back to a physiologic range prior to injection. Alternatively, PRP products such as leukocyte and platelet rich fibrin (L-PRF) do not use anticoagulants and fibrin is formed during the centrifugation step. Evidently, these products have a physiological $\mathrm{pH}$ but cannot be used as injectable.

Importantly, PRP activation is needed to induce the secretion of granule contents i.e. platelet secretome. This occurs spontaneously in blood but is inhibited if the blood is withdrawn in tubes containing anticoagulants. Reversion of anticoagulants inhibition of coagulation and platelet activation can be achieved by several procedures. One possibility is the addition of calcium or thrombin/ $\mathrm{Ca}^{2+}$ to cleave fibrinogen with subsequent polymerization of fibrin monomers. Alternatively, physiological activation can be achieved by injecting the unactivated PRP that once in contact with collagen and other tissue factors will get activated. The mode of delivery of PRP has also to be taken into account, since it is a more involved process than the delivery of a drug or a single recombinant protein. The application protocol and postapplication management involved will have a huge impact on determining whether the potential efficacy is seen.

\begin{tabular}{|c|c|c|c|c|c|c|c|}
\hline $\begin{array}{l}\text { Device } \\
\text { Commercial } \\
\text { name }\end{array}$ & Technology & $\begin{array}{l}\text { FDA } \\
\text { approved }\end{array}$ & $\begin{array}{l}\text { Total } \\
\text { process } \\
\text { time }\end{array}$ & $\begin{array}{l}\text { Disposable } \\
\text { list Price }\end{array}$ & $\begin{array}{l}\text { Increase } \\
\text { above } \\
\text { baseline }\end{array}$ & $\begin{array}{l}\text { Platelet } \\
\text { recovery }\end{array}$ & $\begin{array}{l}\text { PRP } \\
\text { formulations }\end{array}$ \\
\hline $\begin{array}{l}\text { GPS III } \\
\text { (Biomet) }\end{array}$ & Floating Buoy & $510(\mathrm{k})$ & $15 \mathrm{~min}$ & $\$ 700$ & $3.2 x$ & $90 \%$ & L-PRP \\
\hline $\begin{array}{l}\text { Angel } \\
\text { (Arthrex) }\end{array}$ & $\begin{array}{l}\text { Computer Aided } \\
\text { system }\end{array}$ & $510(\mathrm{k})$ & $25 \mathrm{~min}$ & $\$ 495$ & $4.3 x$ & $76 \%$ & L-PRP \\
\hline $\begin{array}{l}\mathrm{ACP} \\
\text { (Arthrex) }\end{array}$ & $\begin{array}{l}\text { Standard } \\
\text { Centrifugation } \\
\text { Thixotropic gel }\end{array}$ & $510(\mathrm{k})$ & $5 \mathrm{~min}$ & $\$ 295$ & $2.1 \pm 2 x$ & $60 \%$ & Pure PRP \\
\hline $\begin{array}{l}\text { AutoloGel } \\
\text { System } \\
\text { (Cytomedix) }\end{array}$ & $\begin{array}{l}\text { Standard } \\
\text { Centrifugation }\end{array}$ & $510(\mathrm{k})$ & $1-2 \mathrm{~min}$ & $\$ 325$ & $1 \mathrm{x}$ & $78 \%$ & L-PRP \\
\hline $\begin{array}{l}\text { GenesisCS } \\
\text { (Emcyte) }\end{array}$ & Direct Siphoning & $510(\mathrm{k})$ & $16 \mathrm{~min}$ & $\$ 1550$ & $\begin{array}{l}10 \pm 3 x \\
(4 \mathrm{ml})\end{array}$ & $68 \pm 17.1 \%$ & L-PRP \\
\hline $\begin{array}{l}\text { Pure PRP } 2 \\
\text { (Emcyte) }\end{array}$ & $\begin{array}{l}\text { Standard } \\
\text { Centrifugation }\end{array}$ & Pending & $5.5 \mathrm{~min}$ & N/A & $8-16 x$ & $76 \%$ & Pure PRP \\
\hline $\begin{array}{l}\text { Harvest }{ }^{\circledR} \\
\text { SmartPrep2 }\end{array}$ & Floating Shelf & $510(\mathrm{k})$ & $16 \mathrm{~min}$ & $\$ 395$ & $4 \mathrm{x}$ & $72.0 \pm 10 \%$ & L-PRP \\
\hline
\end{tabular}




\begin{tabular}{|c|c|c|c|c|c|c|c|}
\hline $\begin{array}{l}\text { Device } \\
\text { Commercial } \\
\text { name }\end{array}$ & Technology & $\begin{array}{l}\text { FDA } \\
\text { approved }\end{array}$ & $\begin{array}{l}\text { Total } \\
\text { process } \\
\text { time }\end{array}$ & $\begin{array}{l}\text { Disposable } \\
\text { list Price }\end{array}$ & $\begin{array}{l}\text { Increase } \\
\text { above } \\
\text { baseline }\end{array}$ & $\begin{array}{l}\text { Platelet } \\
\text { recovery }\end{array}$ & $\begin{array}{l}\text { PRP } \\
\text { formulations }\end{array}$ \\
\hline \multicolumn{8}{|l|}{ BMAC } \\
\hline $\begin{array}{l}\text { Symphony II } \\
\text { (Depuy) }\end{array}$ & Floating shelf & $510(\mathrm{k})$ & $16 \mathrm{~min}$ & $\$ 395$ & $4 \mathrm{x}$ & $72.0 \pm 10 \%$ & L-PRP \\
\hline $\begin{array}{l}\text { Magellan }^{\mathrm{TM}} \\
\text { (Arteriocyte) }\end{array}$ & $\begin{array}{l}\text { Computer Aided } \\
\text { System }\end{array}$ & $510(k)$ & $17 \mathrm{~min}$ & $\$ 350-495$ & $5.1 x$ & $70 \%$ & L-PRP \\
\hline $\begin{array}{l}\text { Dr PRP USA } \\
\text { (Rmedica- } \\
\text { Korea) }\end{array}$ & $\begin{array}{l}\text { Standard } \\
\text { Centrifugation }\end{array}$ & Approved & $12 \mathrm{~min}$ & N/A & N/A & $97 \%$ & L-PRP \\
\hline $\begin{array}{l}\text { Prolo 30-50 } \\
\text { (RM Bio Co, } \\
\text { Ltd.) }\end{array}$ & $\begin{array}{l}\text { Standard } \\
\text { Centrifugation }\end{array}$ & None & N/A & N/A & $4-6 x$ & N/A & L-PRP \\
\hline $\begin{array}{l}\text { Prolo-High } \\
\text { (RM Bio Co } \\
\text { Ltd.) }\end{array}$ & $\begin{array}{l}\text { Standard } \\
\text { Centrifugation }\end{array}$ & None & N/A & N/A & $5-8 x$ & N/A & L-PRP \\
\hline $\begin{array}{l}\text { PRGF®- } \\
\text { Endoret }{ }^{\circledR} \\
\text { (BTI) }\end{array}$ & $\begin{array}{l}\text { Standard } \\
\text { Centrifugation }\end{array}$ & $510(\mathrm{k})$ & $28 \mathrm{~min}$ & N/A & $1-3 x$ & $70 \%$ & Pure PRP \\
\hline $\begin{array}{l}\text { CASCADE® } \\
\text { Autologous } \\
\text { Platelet System } \\
\text { (MTF) }\end{array}$ & $\begin{array}{l}\text { Standard } \\
\text { Centrifugation } \\
\text { Thixotropic gel }\end{array}$ & $510(k)$ & $20 \mathrm{~min}$ & N/A & $1-2 x$ & N/A & Pure PRP \\
\hline $\begin{array}{l}\text { YCellBio PRP } \\
\text { YCELLBIO } \\
\text { MEDICAL }\end{array}$ & $\begin{array}{l}\text { Standard } \\
\text { Centrifugation }\end{array}$ & $510(k)$ & $15 \mathrm{~min}$ & $\$ 80$ & $7-9 X$ & N/A & L-PRP \\
\hline
\end{tabular}

Table 2. Main characteristics of the devices and/or kits used to prepare PRP. Modified from: http:// www.perfusion.com/perfusion/prpdevicesummary.asp

\subsection{Regulatory}

Regulatory requirements for PRPs are not uniform across the world. For example, in the US, PRP is not a product instead administration of PRP is a procedure and is, therefore, not subject to regulation by the FDA. However, the devices used to prepare PRP are regulated by the FDA premarket approval process and have to get a 510(k) clearance.

Devices and procedures destined to prepare PRP are classified for their intended use as class III medical devices and reach the market via premarket approval application. The product is evaluated to ensure that the product is safe and effective and displays consistent performance characteristics. $510(\mathrm{~K})$ premarket notification exists for products that are similar to those 
already marketed usually called predicate device. In these cases $510(\mathrm{k})$ clearance is evaluated only for substantial equivalency.

Table 1 shows devices and/or kits for PRP preparation

At the European level there is no harmonized regulatory framework for PRP therapies, and each country has its own approach to PRP regulation within the jurisdiction of national authorities. Devices must comply with Class II-a medical device directive 93/42/EEC. Device approval in EU is overseen in each EU country by a governmental body called a Competent Authority. Instead, the surgical use of PRP can be considered as an autologous graft within the surgical procedure as regulated by Directive 2004/23/EC.

Of note, if regulatory requirements for PRP therapies were over-interpreted, unnecessary work derived therein will increase costs and hamper the clinical use of PRP therapies. This hypothetical situation would be prejudicial for many patients since advancements in PRP science can provide effective treatments for pathologies with substantial social and economic burden.

\subsubsection{Reimbursement}

Currently most insurance plans do not reimburse for PRP treatment due to the lack of data about their efficacy. Interestingly, in the US Category III, code 0232T is used for emerging technologies and applies for nonsurgical uses of PRP. This code allows data collection to be used to document widespread use for FDA approval and potential reimbursement. Besides, this code will allow the AMA (American Medical Association) to track the use of PRP, since codes $\mathrm{T}$ are considered experimental they will require pre-authorization for payment. If a physician feels that the patient would benefit from PRP injections, typically as a step to avoid a more costly and invasive procedure preauthorization for PRP reimbursement should be requested. Presentation of cost savings rationale can be the key to successful preauthorization. In general managers are concerned about physician's plans to get injured patients back to productivity or work.

\section{Translational uses of PRP biotechnology clinical relevance of PRPs}

The goal of this section is not to provide an exhaustive overview of current clinical studies but to identify and briefly describe the miscellaneous clinical applications. PRP is considered investigational because currently, there is insufficient evidence to support the use of PRP for all the indications included below.

The use of PRPs has extended to multiple clinical fields and novel applications are emerging to meet varied clinical needs. The increasing use of PRPs in sports medicine, (after withdrawal of restrictions imposed by the IOC International Olympic Committee) and PRP applications in areas such as dentistry and plastic surgery is expected to drive the financial growth of PRPs, that was estimated in the US market as CAGR annual growth rate of $14 \%$ from 2009 to 2016 (\$45m in 2009 will reach \$126m in 2016) (http://www.researchviews.com/healthcare/medical/ 
orthopedicdevices/Viewpoints.asp $\quad x$ ?sector=Orthopedic\%20Devices\&DocID=10728). The diffusion of PRP is attributed to the biosafety of the product due to its autologous origin.

In general, clinical uses of PRP can be categorized in two. First surgical applications, when PRP is used in surgery as an aid to enhance repair, not only of target tissues but PRP also aims to enhance the healing of all the adjacent tissues damaged during the procedure, and secondly conservative uses of PRP, most often involving more than one application and used in outpatient settings. Besides, the use of PRP associated to other medical procedures (laser therapies, etc) offers potential to enhance such procedures. Table 3 and Table 4.

\subsection{Treatment of non-healing wounds}

PRP has been used to treat non-healing wounds for more than 2 decades. In fact, the topical management of chronic leg ulcers was the first clinical application of platelets outside the blood stream with healing purposes. Theoretically PRP or its derivatives are stimulants for nonhealing wounds; the goal is to re-activate healing. The rapid formation of granulation tissue can prevent further deep tissue involvement and associated co-morbidities.

Complex non-healing wounds can have different etiologies including pressure ulcers, diabetes, venous, arterial, or surgical trauma. Impaired wound healing is the major complication that results in the development of chronic wounds often leading to amputations as often occurs in the diabetic foot. Components of lower extremity amputations in the diabetic patient include ulceration $(85 \%)$, faulty wound healing $(81 \%)$ initial minor trauma $(81 \%)$, neuropathy $(61 \%)$, infection (59\%) gangrene (55\%) and ischemia (46\%) (38]. Actually, the wound healing society treatment guidelines for diabetic ulcers advises re-evaluation of the wound and treatment based on failure to reach a $40 \%$ reduction of initial wound size by week 4 (39]. Cost for amputations has been estimated to be between $\$ 20.000$ and $\$ 60.000$ per case. PRP is deemed useful in this context because it may provide a way to reduce this cost burden to society.

Several RCT have provided data about the efficacy of PRP or PRP derivatives in non-healing wounds. The initial platelet product known as PDWHF (platelet derived wound healing factors) stimulated the formation of granulation tissue in chronic leg ulcers [40]. Later, PDWHF of pooled donors was also examined in the treatment of diabetic ulcers (41]. In general, concomitant pathologies such as diabetes do not hinder the therapeutic effects of PRP, and autologous PRP is effective in the diabetic foot [42-43] or systemic sclerosis [44].

Despite several studies reporting the benefits of PRP in this setting, a recent meta-analysis of ulcer care studies and PRP failed to show any statistically relevant difference favoring PRP for the treatment of chronic wounds. Nevertheless, conclusions are not sound because they are based on 9 RCTs with high or unclear risk of bias [45]. Additional evidences complementary to RCT data can be obtained from practice based medicine and observational studies. These data obtained in a real-world setting provide pragmatic evidences of PRP benefits.

Actually, some PRP manufacturers such as Cytomedix, AutoloGel ${ }^{\mathrm{TM}}$ have created wound registries to evaluate the use of PRP and calculate cost savings based on mean treatment times; this is realistic using patients in pretreatment run-in periods as their own controls during standard wound care treatment [46]. 
The reduction in treatment time should impact clinical and financial decisions. Significant clinical outcomes indicated many previously nonresponsive wounds began actively healing in response to PRP therapy. Cost effectiveness analysis comparing the potential economic benefit of PRP to alternative therapies in treating non-healing diabetic foot ulcers, using an economic model based on peer-reviewed data showed that PRP resulted in improved quality of life and lower cost of care over 5 -year period than other treatment modalities for non-healing diabetic ulcers [47].

\subsection{Maxillofacial and oral surgery}

The field of PRP gained new impetus at the end of the nineties when maxillofacial surgeons and dentists introduced PRP to augment oral reconstruction procedures. Since then a number of protocols have been developed for different applications. These include socket filling after molar extractions, implant surgery, PRP mixed with bone grafts during osteodistraction, and in the treatment of mandibular tumor resection. Numerous articles describe earlier stabilization of dental implants when PRP is used to enhance the properties of bone grafts, and to modulate the inflammatory status in the surrounding soft tissues.

The utility in several of these procedures seems evident. However, after meta-analyzing 24 studies addressing the use of PRP in the surgical treatment of periodontal diseases, it was concluded that PRP exerts a positive effect only when used with graft materials for the treatment of intrabony defects, but not in guided tissue regeneration. No significant benefit of PRP was found for the treatment of gingival recessions [48].

In sinus augmentation surgery the combination of PRP with autologous bone graft led to increased bone density at 6 months but not at three months [49].

The use of PRP in children is less known because they need little help for healing since young cells and young blood has stronger healing potential and plasticity when compared to adults. However, in the most frequent congenital facial malformation, i.e. cleft lip and palate, the use of PRP is being investigated [50-53]. The goal here is to reestablish the maxillofacial arch and to close any oro-nasal communication. Besides, PRP is used in the closure of recurrent cleft palate fistulas.

\subsection{Plastic surgery and dermatology}

A recent review in plastic surgery including 15 randomized controlled studies and 25 casecontrols showed that the outcomes were favorable in three main PRP indications: wound healing, fat grafting and bone grafting [54].

PRP is used in breast reconstruction associated to fat grafts because it enhances the survival of fat grafts that otherwise had a tendency to be resorbed by the organism. Similarly, the outcome of plastic reconstruction using skin grafts can be improved taking advantage of the pro-survival effects of PRP.

The use of PRP reduced recovery time in facial rejuvenation. In fact the addition of PRP to lipofilling procedures resulted in a significant reduction in the number of days needed to 
recover before returning to work or restart social activities. Also the aesthetic outcome was significantly better with PRP [55].

Combined treatments as fat graft, laser $\mathrm{CO} 2$ and PRP showed clinical benefits in the treatment of atrophic and contractile scars [56].

PRP combined with erbium fractional laser therapy is effective for treating acne scars or acne, at the same time PRP enhances the recovery of laser damaged skin [57].

PRP injected into the scalp is also used to manage androgenetic alopecia [58]. When the efficacy of the interventions was examined in 64 patients, half of the patients showed a clinically meaningful improvement [59]. PRP is also used in hair transplantation [60]. In this situation, PRP shortens the time for hair formation.

\subsection{Treatment of orthopedic problems}

The use of PRP to solve clinical problems in orthopedics has increased with impetus in the past five years the main reason can be the biosafety of the treatment and the fact that actual strategies for management are insufficient. PRP is used in open and arthroscopic surgery and as a conservative treatment for the management of chronic pathologies, most importantly tendinopathies, chondropathies and osteoarthritis. Main properties are attributed to modulatory effects on inflammation and angiogenesis along with reduction in pain [61-63].

Research in orthopedics encompasses a wide range of applications. In sports medicine, physicians are more deeply engaged in conservative management of tendinopathies and muscle injuries

Proposed clinical and surgical applications include spinal-fusion, osteoarthritis [hip and knee), tendinopathy enhancement of healing after ACL reconstruction and muscle strains. The challenge is to show that PRP is superior to the optimal available treatment.

\subsubsection{Bone regeneration}

In some applications PRP is used as a coadjuvant associated to autologous or homologous graft and also to bone marrow graft. There is no compelling evidence to demonstrate the efficacy of PRP alone in facilitating the union of long bones for union of tibial osteotomies or pseudoarthrosis or fractures [64). An randomized study involving 21 participants compared PRP+allogeneic graft versus allogeneic bone alone in patients undergoing tibial osteotomy in the medial compartment in patients with OA [65]. There was a significant difference in the proportion of bones that were united after one year in favor of PRP but evidence from a single trial is insufficient to support routine interventions with PRP.

\subsubsection{Lumbar fusion and intervertebral disc degeneration}

Posterolateral arthrodesis in lumbar spine surgery was enhanced when PRP was combined with cancellous bone graft as shown by densitometry in a prospective study [66]. However, a randomized clinical study did not show any benefit when PRP is used with autologous bone in mono-segmental posterior lumbar interbody fusion [67]. 
Intervertebral disc degeneration is also common in orthopedics and current treatments are of limited value to enhance the regenerative process. In fact some studies point out the efficacy of PRP in reversing the degenerative trend of the intervertebral discs based on basic science research [68]. However this application lacks translation in published reports.

\subsubsection{Osteoarthritis}

The efficacy of PRP has been most studied in knee osteoarthritis while few clinical data are available about the therapeutic effects in hip OA.

There are several randomized clinical trials comparing the efficacy of PRP treatment with HA administration. Also PRP has been compared with placebo administration. Two recent metaanalysis $[69,70]$ concluded that multiple PRP injections ameliorate pain and improves function and tends to be more effective that HA administration. Patients with lower levels of knee degeneration achieve better results than more advanced knee deterioration. Although less investigated, PRP injections in the hip ameliorate symptomatology and function, however the clinical level of evidence is low and more clinical studies are needed before claiming therapeutic effects in this joint [71].

\subsubsection{Tendon pathology}

Most studies in tendon pathology involve guided injections of PRP. Indeed, the development of real-time imaging techniques such ultrasonography enhances the safety and accuracy of PRP delivery during percutaneous management. Consequently, investigation on the efficacy of PRPs for managing chronic tendinopathies has grown in the last years and the quality of the studies has improved considerably. Limitations of observational studies have been overcome by level I and level 2 clinical trials. However due to tendon diversity and function, the various PRP products and the diversity of application protocols, quantitative synthesis and meta-analyses are difficult to perform.

Most frequent upper limb tendinopathies involve the supraspinatus and the medial and lateral epicondyle. In these pathologies, the quality of clinical studies is high/moderate. A quantitative synthesis evaluating the efficacy of PRP as an adjuvant in rotator cuff arthroscopy failed to show any benefit associated to PRP. The only uncertainty in favor of PRP is that it may decrease the proportion of retears, but this needs further confirmation [72].

Ultrasound guided injections and real-time follow-up has fueled the use of PRP in tendinopathies

A recent metaanalysis examining the conservative management of tendinopathy has shown that PRP provide some benefits in pain [61]. Moreover, subgroup analysis showed a modest reduction of pain in epicondylitis [73]. However, major limitations for pooling data and drawing firm conclusions comprise different outcome measurements and follow-up periods.

The most commonly treated tendons in the lower limb were Achilles, the patellar tendon and the plantar fascia. PRP shows potential benefits in these anatomical locations, current eviden- 
ces are encouraging but limited. The need is clear to compare PRP treatment with the most adequate control for each condition.

\subsubsection{Muscle injuries}

PRP injections are used in professional athletes; the goal is to accelerate muscle healing, and avoid relapses through true muscle regeneration, i.e. absence of scar tissue. Especially in elite athletes the goal is to achieve rapid healing and resume competition faster than with conventional care. Although case series provide promising results, two recent randomized controlled trials showed divergent results [74,75]. Protocols and PRP formulations were different in both studies, thus further research is warranted.

\subsection{Treatment of eye problems}

\subsubsection{Macular hole}

Platelet concentrates were used in the $90 \mathrm{~s}$ as an adjunct to macular hole healing. PRP is an autologous alternative to fibrin glue with much more biological activity conferred by hundreds of GFs and cytokines stored in alpha-granules. The efficacy of platelet concentrates was examined in a multicenter double blind study involving 53 eyes in the experimental group and 57 eyes in the control group. Injection of autologous platelet concentrates during macular hole surgery improved significantly the anatomic success of the intervention but did not influence visual acuity [76].

\subsubsection{Dry eye}

Autologous serum administered topically has been used to treat dry eye symptoms because it can improve not only lubrication but also enhance lacrimal production since its composition includes GFs important in this context such as EGF. However, after metaanalysing current studies there were inconsistency in relation to the benefits provided by autologous serum [77].

As an alternative, PRP derivatives mainly the PRP released supernatant or the PRP lysate are being investigated to improve dry eye conditions, administered topically. Alternatively, in severe cases PRP is injected adjacent to the lacrimal gland [78]. Results indicate a significant increase in lacrimal volume and patient's self-reported improvements. PRP also enhanced epithelial status after LASIK but did not affect the recovery of corneal sensitivity.as evaluated in a controlled study in which the contralateral eye was used as control [79].

\subsubsection{Corneal ulcers}

Perforated corneal ulcers have been treated with PRP fibrin in a reduced number of patients ( $\mathrm{N}=11=$. In all cases the corneal perforation was sealed after 3-5 days of stability of the membrane in the ulcer [80]. When PRP eyedrops were compared to autologous serum eyedrops in the treatment of persistent epithelial defects PRP was more efficient than serum [81]. After photorefractive keratectomy, the use of PRP enhanced wound healing and reduced haze formation [82] 
In a prospective controlled study in acute ocular chemical injury PRP eyedrops as adjunct to standard care was superior to artificial tears, autologous platelet lysate was also effective for the treatment of refractory ocular GVDH in unresponsive patients [83].

\subsubsection{Other therapeutic applications}

Some anecdotic uses of PRP in urology for fistula repair [84], in the management of infantile extravasation injury [85], and in gynecology for vaginal prolapse [86-87] have been published.

\section{Challenges ahead}

As PRP is eminently a translational technology, challenges must be addressed through three interlinked angles: scientific, clinical and socioeconomic.

From the scientific aspect, evidence continues to build for the mechanisms of PRP in tissue repair regulating the behavior of different cell types. At present we have a more complete picture on how PRP influences healing mechanisms however, we do not know enough to design formulations for specific medical problems. Difficulties to advance are attributed to the lack of characterization of the host tissue. In fact, the host response to PRP administration will drive the healing mechanisms. The host response invariably starts with activation of the immune innate system as a result of PRP administration. Moreover, considering the local $\mathrm{pH}$, $\mathrm{O}_{2}$ levels, and cellular conditions of the host (i.e. number of dying cells apoptotic or necrotic) is important not only in terms of GFs and cytokine stability but also to have information about the main mechanism affected.

Clinical challenges: PRP research may eventually lead to superior therapies. The translational imperative is making PRP formulation effective in defined indications. The challenge is to customize PRP formulations. Essentially a single formulation cannot fulfill every need, from treating a degenerative knee to repairing a pseudo-arthritic condition.

The modest benefits achieved with clinical trials addressing PRP efficacy should not reduce our motivation, instead we need to understand better the underlying mechanisms so that the most appropriate indications can be found and appropriate trials conducted to test the specific indications. Novel approaches to clinical trial design shall recognize that the efficacy of these therapies will be dependent upon delivery protocol as well as the PRP product itself.

Socioeconomic challenges: we should consider carefully the potential of PRPs to reduce costs in chronic diseases. This could be achieved by the creation of proper registries and economic models considering the costs generated in pre-treatment run-in periods. In patients with recalcitrant pathologies, candidates to surgical interventions, economical algorithms will help to estimate savings attributable to surgical and post-surgical costs relative to the conservative management. 


\begin{tabular}{|c|c|}
\hline \multirow{2}{*}{ Cardiac surgery } & Coronary artery bypass graft surgery* \\
\hline & Aorta surgery* \\
\hline \multirow{5}{*}{ Plastic surgery } & Breast reconstruction ${ }^{* *}$ \\
\hline & Infected high-energy soft tissue injuries* \\
\hline & Skin grafts** \\
\hline & Fat grafts*** \\
\hline & Pilodinal sinus abscesses* \\
\hline \multirow{2}{*}{ Pediatric surgery } & Alveoloplasty of cleft palate* \\
\hline & Extravasation injury (premature infants) ${ }^{*}$ \\
\hline \multirow{6}{*}{ Maxillofacial and oral surgery } & Molar extractions ${ }^{* * *}$ \\
\hline & Implant surgery ${ }^{* * *}$ \\
\hline & Osteodistraction ${ }^{* *}$ \\
\hline & Periodontal disease ${ }^{* *}$ \\
\hline & Mandibular tumor resection ${ }^{* *}$ \\
\hline & Sinus lift** \\
\hline \multirow{2}{*}{ Urology } & Uretracutaneous fistula repair * \\
\hline & Vesicovaginal fistula* \\
\hline \multirow[t]{5}{*}{ Gynecology } & Vaginal prolapse* \\
\hline & Non-union (aseptic pseudo-arthrosis) ${ }^{*}$ \\
\hline & Tendon surgery* \\
\hline & Morton neuroma* \\
\hline & Peripheral nerve regeneration* \\
\hline \multirow[t]{5}{*}{ Orthopedics and Arthroscopic surgery } & ACL reconstruction ${ }^{* * *}$ \\
\hline & Rotator cuff surgery ${ }^{* * *}$ \\
\hline & Lumbar interbody fusion* \\
\hline & Tibial osteotomy* \\
\hline & Hip conditions (sacroiliac joint dysfunction)* \\
\hline
\end{tabular}

*** Broadly used, that is RCTs, several clinical evidences and different levels of evidence

** Moderate use, case series and at least one controlled study

* Anecdotic use, case series or an isolated prospective cohort

Table 3. Miscellaneous applications of PRPs in open surgery

\begin{tabular}{|c|c|}
\hline & Macular hole ${ }^{* *}$ \\
\hline \multirow{5}{*}{ Eye disease } & Restoration of human lacrimal function (dry eye) ${ }^{* *}$ \\
\hline & Corneal ulcers and lesions ${ }^{* *}$ \\
\hline & Chemical acute wounds \\
\hline & Neurotrophic wounds \\
\hline & epithelial \\
\hline
\end{tabular}




\begin{tabular}{|c|c|}
\hline & Refractory ocular GVDH* \\
\hline \multirow{2}{*}{ Cardiology } & Complications of sternotomy ${ }^{* *}$ \\
\hline & Severe deep sternal wound infection ${ }^{* *}$ \\
\hline \multirow{10}{*}{ Dermatology } & Non-healing ulcers*** \\
\hline & Diabetic ulcer \\
\hline & Neurogenic \\
\hline & Arterial \\
\hline & traumatic \\
\hline & Pressure ulcers \\
\hline & Vascular ulcers \\
\hline & Treatment of striae distensae \\
\hline & Androgenetic alopecia* \\
\hline & Peripheral neuropathy ${ }^{*}$ \\
\hline \multirow{7}{*}{ Sports Medici } & Chondropathy and Osteoarthritis ${ }^{* * *}$ \\
\hline & Tendinopathies*** \\
\hline & Muscle injuries** \\
\hline & s Ligament injuries* \\
\hline & Fasciitis plantar** \\
\hline & Recalcitrant hindfoot and ankle disease ${ }^{* *}$ \\
\hline & Per-cutaneous non-unions* \\
\hline
\end{tabular}

Table 4. Conservative clinical applications of PRP therapies

\section{Author details}

I. Andia ${ }^{1 *}$, E. Rubio-Azpeitia ${ }^{1}$, J.I. Martin ${ }^{1}$ and M. Abate $^{2}$

*Address all correspondence to: iandia2010@hotmail.com

1 BioCruces Health Research Institute/Cruces University Hospital, Barakaldo, Spain

2 Department of Medicine and Science of Aging, University G. d'Annunzio, Chieti-Pescara, Italy

\section{References}

[1] Oerlemans AJM, van Hoeck MEC, van Leeuwen E, Dekkers WJM. Hype and expectations in tissue engineering. Reg Med 2014;9(1):113-122

[2] Li MD, Atkins H, Bubela T. The global landscape of stem cell clinical trials. Reg Med 2014;9(1):27-39 
[3] Närhi MO, Nordström K. Regulation of cell based therapeutic products intended for human applications in the EU. Reg Med 2014;9(3):327-351

[4] Gilbert SF, Sarkar S. Embracing complexity: organicism for the 21st century. Dev Dyn. 2000 Sep;219(1):1-9

[5] Godwin JW, Rosenthal N. Scar-free wound healing and regeneration in amphibians: immunological influences on regenerative success. Differentiation 2014; 87:66-75

[6] Godwin JW, Pinto AR, Rosenthal NA. Macrophages are required for adult salamander limb regeneration. PNAS 2013

[7] Fukaya Y, Kuroda M, Aoyagi Y, Asada S, Kubota Y, Okamoto Y, Nakayama T, Saito Y, Satoh K, Bujo H. Platelet-rich plasma inhibits the apoptosis of highly adipogenic homogeneous preadipocytes in an in vitro culture system. Exp Mol Med. 2012 May 31;44(5):330-9

[8] Zargar Baboldashti N, Poulsen RC, Franklin SL, Thompson MS, Hulley PA. Plateletrich plasma protects tenocytes from adverse side effects of dexamethasone and ciprofloxacin. Am J Sports Med. 2011 Sep;39(9):1929-35.

[9] Peng Y, Huang S, Wu Y, Cheng B, Nie X, Liu H, Ma K, Zhou J, Gao D, Feng C, Yang $\mathrm{S}, \mathrm{Fu} X$. Platelet rich plasma clot releasate preconditioning induced PI3K/AKT/NFKB signaling enhances survival and regenerative function of rat bone marrow mesenchymal stem cells in hostile microenvironments. Stem Cells Dev. 2013;22(24):3236-51

[10] Griffiths S, Baraniak PR, Copland IB, Nerem RM, McDevitt TC. Human platelet lysate stimulates high-passage and senescent human multipotent mesenchymal stromal cell growth and rejuvenation in vitro. Cytotherapy. 2013 Dec;15(12):1469-83

[11] Andia I, Maffulli N. Platelet rich plasma for muscle injury and tendinopathy. Sports Medicine Arthroscop Rev 2013 Dec;21(4):191-8

[12] Andia I, Abate M. Platelet Rich Plasma (PRP): Underlying Biology and Clinical Correlates. Reg Med 2013 Sep;8(5):645-58.

[13] Andia I,Rubio-Azpeitia E, Maffulli N. Hyperuricemic PRP in tendon cells.BioMed Res Int 2014 http://dx.doi.org/10.1155/2014/926481

[14] Davis MJ, Tsang TM, Qiu Y, Dayrit JK, Freij JB, Huffnagle GB, Olszewski MA. Macrophage M1/M2 polarization dynamically adapts to changes in cytokine microenvironments in Cryptococcus neoformans infection. MBio. 2013 Jun 18;4(3):e00264-13

[15] Gleissner CA. Macrophage phenotype modulation by CXCL4 atherosclerosis. Frontiers Physiol 2012;3:1-7

[16] Vidal B, Serrano AL, Tjwa M, Suelves M, Ardite E, De Mori R, Baeza-Raja B, Martínez de Lagrán M, Lafuste P, Ruiz-Bonilla V, Jardí M, Gherardi R, Christov C, Dierssen M, Carmeliet P, Degen JL, Dewerchin M, Muñoz-Cánoves P. Fibrinogen drives 
dystrophic muscle fibrosis via a TGFbeta/alternative macrophage activation pathway. Genes Dev. 2008 Jul 1;22(13):1747-52.

[17] Bir SC, Esaki J, Marui A, Sakaguchi H, Kevil CG, Ikeda T, Komeda M, Tabata Y, Sakata R. Therapeutic treatment with sustained-release platelet-rich plasma restores blood perfusion by augmenting ischemia-induced angiogenesis and arteriogenesis in diabetic mice. J Vasc Res. 2011;48(3):195-205.

[18] Richardson TP1, Peters MC, Ennett AB, Mooney DJ. Polymeric system for dual growth factor delivery. Nat Biotechnol. 2001 Nov;19(11):1029-34.

[19] Dellavalle A, Maroli G, Covarello D, Azzoni E, Innocenzi A, Perani L, Antonini S, Sambasivan R, Brunelli S, Tajbakhsh S, Cossu G. Pericytes resident in postnatal skeletal muscle differentiate into muscle fibres and generate satellite cells. Nat Commun. 2011 Oct 11;2:499.

[20] Cappellari O, Cossu G. Pericytes in development and pathology of skeletal muscle. Circ Res. 2013 Jul 19;113(3):341-7.

[21] Andia I, Abate M. Platelet rich plasma injections for tendinopathy and osteoarthritis. Int J Clin Rheumatol 2012; 7(4): 397-412

[22] Lev EI, Estrov Z, Aboulfatova K, Harris D, Granada JF, Alviar C, Kleiman NS, Dong JF. Potential role of activated platelets in homing of human endothelial progenitor cells to subendothelial matrix. Thromb Haemost. 2006 Oct;96(4):498-504

[23] Lee JK, Lee S, Han SA, Seong SC, Lee MC. The effect of platelet-rich plasma on the differentiation of synovium-derived mesenchymal stem cells. J Orthop Res. 2014;32(10):1317-25

[24] Chen L, Dong SW, Tao X, Liu JP, Tang KL, Xu JZ. Autologous platelet-rich clot releasate stimulates proliferation and inhibits differentiation of adult rat tendon stem cells towards nontenocyte lineages. J Int Med Res. 2012;40(4):1399-409

[25] Li H, Usas A, Poddar M, Chen CW, Thompson S, Ahani B, Cummins J, Lavasani M, Huard J. Platelet-rich plasma promotes the proliferation of human muscle derived progenitor cells and maintains their stemness. PLoS One. 2013 Jun 7;8(6):e64923.

[26] Rubio-Azpeitia E, Andia I. Partnership between platelet-rich plasma and mesenchymal stem cells: in vitro experience. Muscles Ligaments Tendons J. 2014 May 8;4(1): 52-62.

[27] Madduri S, Gander B. Schwann cell delivery of neurotrophic factors for peripheral nerve regeneration. J Peripher Nerv Syst. 2010;15(2):93-103.

[28] Emel E, Ergün SS, Kotan D, Gürsoy EB, Parman Y, Zengin A, Nurten A. Effects of insulin-like growth factor-I and platelet-rich plasma on sciatic nerve crush injury in a rat model. J Neurosurg. 2011 Feb;114(2):522-8. 
[29] Farrag TY, Lehar M, Verhaegen P, Carson KA, Byrne PJ. Effect of platelet rich plasma and fibrin sealant on facial nerve regeneration in a rat model. Laryngoscope. 2007 Jan;117(1):157-65.

[30] Sariguney Y, Yavuzer R, Elmas C, Yenicesu I, Bolay H, Atabay K. Effect of plateletrich plasma on peripheral nerve regeneration. J Reconstr Microsurg. 2008;24(3): 159-67.

[31] Cho HH, Jang S, Lee SC, Jeong HS, Park JS, Han JY, Lee KH, Cho YB. Effect of neural-induced mesenchymal stem cells and platelet-rich plasma on facial nerve regeneration in an acute nerve injury model. Laryngoscope. 2010 May;120(5):907-13.

[32] Zheng C, Zhu Q, Liu X, Huang X, He C, Li J, Quan D. Improved peripheral nerve regeneration using acellular nerve allografts loaded with platelet-rich plasma. Tissue Eng Part A. 2014 Jun 5.

[33] Kaplan S, Pişkin A, Ayyildiz M, Aktaş A, Köksal B, Ulkay MB, Türkmen AP, Bakan F, Geuna S. The effect of melatonin and platelet gel on sciatic nerve repair: an electrophysiological and stereological study. Microsurgery. 2011 May;31(4):306-13.

[34] Anjayani S, Wirohadidjojo YW, Adam AM, Suwandi D, Seweng A, Amiruddin MD. Sensory improvement of leprosy peripheral neuropathy in patients treated with perineural injection of platelet-rich plasma. Int J Dermatol. 2014 Jan;53(1):109-13.

[35] Knighton DR, Ciresi KF, Fiegel VD, Austin LL, Butler EL. Classification and treatment of chronic nonhealing wounds. Successful treatment with autologous plateletderived wound healing factors (PDWHF). Ann Surg. 1986 Sep;204(3):322-30

[36] Ferrari M, Zia S, Valbonesi M, Henriquet F, Venere G, Spagnolo S, Grasso MA, Panzani I. A new technique for hemodilution, preparation of autologous platelet-rich plasma and intraoperative blood salvage in cardiac surgery. Int J Artif Organs. 1987 Jan;10(1):47-50

[37] Dohan Ehrenfest D.M., Andia I., Zumstein M.A., Zhang, Pinto N.R., Bielecki T. Classification of platelet concentrates (Platelet-Rich Plasma-PRP, Platelet-Rich FibrinPRF) for topical and infiltrative use in orthopedic and sports medicine: current consensus, clinical implications and perspectives. MLTJ vol4 (1): 3 - 9, R

[38] Pecoraro RE, Reiber GE, Burgess EM. Pathways to diabetic limb amputation. Basis for prevention. Diabetes Care. 1990;13(5):513-21.

[39] Steed DL, Attinger C, Colaizzi T, Crossland M, Franz M, Harkless L, Johnson A, Moosa H, Robson M, Serena T, Sheehan P, Veves A, Wiersma-Bryant L. Guidelines for the treatment of diabetic ulcers. Wound Repair Regen. 2006;14(6):680-92.

[40] Knighton DR, Ciresi K, Fiegel VD, Schumerth S, Butler E, Cerra F. Stimulation of repair in chronic, nonhealing, cutaneous ulcers using platelet-derived wound healing formula. Surg Gynecol Obstet. 1990 Jan;170(1):56-60 
[41] Steed DL, Goslen JB, Holloway GA, Malone JM, Bunt TJ, Webster MW. Randomized prospective double-blind trial in healing chronic diabetic foot ulcers. CT-102 activated platelet supernatant, topical versus placebo. Diabetes Care. 1992;15(11):1598-604

[42] de Leon JM, Driver VR, Fylling CP, Carter MJ, Anderson C, Wilson J, Dougherty RM, Fuston D, Trigilia D, Valenski V, Rappl LM. The clinical relevance of treating chronic wounds with an enhanced near-physiological concentration of platelet-rich plasma gel. Adv Skin Wound Care. 2011 Aug;24(8):357-68

[43] Carter MJ, Fylling CP, Parnell LK. Use of platelet rich plasma gel on wound healing: a systematic review and meta-analysis. Eplasty. 2011;11:e38. Epub 2011 Sep 15.

[44] Kanemaru H, Kajihara I, Yamanaka K, Igata T, Makino T, Masuguchi S, Fukushima $\mathrm{S}$, Jinnin M, Ihn H. Platelet-rich plasma therapy is effective for the treatment of refractory skin ulcers in patients with systemic sclerosis. Mod Rheumatol. 2014 Jun $16: 1-2$.

[45] Martinez-Zapata MJ, Martí-Carvajal AJ, Solà I, Expósito JA, Bolíbar I, Rodríguez L, Garcia J. Autologous platelet-rich plasma for treating chronic wounds. Cochrane Database Syst Rev. 2012

[46] Carter MJ, Fylling CP, Li WW, de Leon J, Driver VR, Serena TE, Wilson J. Analysis of run-in and treatment data in a wound outcomes registry: clinical impact of topical platelet-rich plasma gel on healing trajectory. Int Wound J. 2011 Dec;8(6):638-50.

[47] Dougherty EJ. An evidence-based model comparing the cost-effectiveness of plateletrich plasma gel to alternative therapies for patients with nonhealing diabetic foot ulcers. Adv Skin Wound Care. 2008 Dec;21(12):568-75.

[48] Del Fabbro M, Bortolin M, Taschieri S. Is autologous platelet concentrate beneficial for post-extraction socket healing? A systematic review. Int J Oral Maxillofac Surg. 2011 Sep;40(9):891-900

[49] Khairy NM, Shendy EE, Askar NA, El-Rouby DH. Effect of platelet rich plasma on bone regeneration in maxillary sinus augmentation (randomized clinical trial). Int J Oral Maxillofac Surg. 2013 Feb;42(2):249-55

[50] González-Sánchez JG, Jiménez-Barragán K. Closure of recurrent cleft palate fistulas with plasma rich in growth factors. Acta Otorrinolaringol Esp. 2011 Nov-Dec;62(6): 448-53.

[51] Lee C, Nishihara K, Okawachi T, Iwashita Y, Majima HJ, Nakamura N. A quantitative radiological assessment of outcomes of autogenous bone graft combined with platelet-rich plasma in the alveolar cleft. Int J Oral Maxillofac Surg. 2009 Feb;38(2): $117-25$

[52] Luaces-Rey R, Arenaz-Búa J, Lopez-Cedrún-Cembranos JL, Herrero-Patiño S, Sironvalle-Soliva S, Iglesias-Candal E, Pombo-Castro M. Is PRP useful in alveolar cleft re- 
construction? Platelet-rich plasma in secondary alveoloplasty. Med Oral Patol Oral Cir Bucal. 2010 Jul 1;15(4):e619-23

[53] Marukawa E, Oshina H, Iino G, Morita K, Omura K. Reduction of bone resorption by the application of platelet-rich plasma (PRP) in bone grafting of the alveolar cleft. J Craniomaxillofac Surg. 2011;39(4):278-83

[54] Sommeling CE(1), Heyneman A, Hoeksema H, Verbelen J, Stillaert FB, Monstrey S. The use of platelet-rich plasma in plastic surgery: a systematic review. J Plast Reconstr Aesthet Surg. 2013;66(3):301-11.

[55] Willemsen JC, van der Lei B, Vermeulen KM, Stevens HP. The Effects of Platelet-Rich Plasma on Recovery Time and Aesthetic Outcome in Facial Rejuvenation: Preliminary Retrospective Observations. Aesthetic Plast Surg. 2014 Jul 2. [Epub ahead of print]

[56] Nita AC, Orzan OA2, Filipescu M3, Jianu D. Fat graft, laser $\mathrm{CO}_{2}$ and platelet-richplasma synergy in scars treatment. J Med Life. 2013;6(4):430-3.

[57] Zhu JT, Xuan M, Zhang YN, Liu HW, Cai JH, Wu YH, Xiang XF, Shan GQ, Cheng B. The efficacy of autologous platelet-rich plasma combined with erbium fractional laser therapy for facial acne scars or acne. Mol Med Rep. 2013 Jul;8(1):233-7

[58] Cervelli V, Garcovich S, Bielli A, Cervelli G, Curcio BC, Scioli MG, Orlandi A, Gentile P.The effect of autologous activated platelet rich plasma (AA-PRP) injection on pattern hair loss: clinical and histomorphometric evaluation. Biomed Res Int. 2014;2014:760709

[59] Schiavone G1, Raskovic D, Greco J, Abeni D. Platelet-rich plasma for androgenetic alopecia: a pilot study. Dermatol Surg. 2014;40(9):1010-9

[60] Miao Y, Sun YB, Sun XJ, Du BJ, Jiang JD, Hu ZQ. Promotional effect of platelet-rich plasma on hair follicle reconstitution in vivo. Dermatol Surg. 2013;39(12):1868-76

[61] Andia I, Latorre PM, Gomez MC, Burgos-Alonso N, Abate M, Maffulli N. Plateletrich plasma in the conservative treatment of painful tendinopathy: a systematic review and meta-analysis of controlled studies. Br Med Bull. 2014 Jun;110(1):99-115 R

[62] Andia I, Maffulli N. Platelet Rich Plasma for patellar tendon and MCL injuries. J Knee Surg. 2014

[63] Andia I, Maffulli N. Platelet-rich plasma for managing pain and inflammation in osteoarthritis. Nat Rev Rheumatol 2013 Dec;9(12):721-30

[64] Griffin XL, Wallace D, Parsons N, Costa ML. Platelet rich therapies for long bone healing in adults. Cochrane Database Syst Rev. 2012 Jul 11;7:CD009496.

[65] Lenza M, Ferraz Sde B, Viola DC, Santos OF, Cendoroglo Neto M, Ferretti M. Platelet-rich plasma for long bone healing. Einstein (Sao Paulo). 2013;11(1):122-7.

[66] Tarantino R, Donnarumma P, Mancarella C, Rullo M, Ferrazza G, Barrella G, Martini $S$, Delfini R. Posterolateral arthrodesis in lumbar spine surgery using autologous pla- 
telet-rich plasma and cancellous bone substitute: an osteoinductive and osteoconductive effect. Global Spine J. 2014 Aug;4(3):137-42.

[67] Sys J, Weyler J, Van Der Zijden T, Parizel P, Michielsen J.Platelet-rich plasma in mono-segmental posterior lumbar interbody fusion. Eur Spine J. 2011;20(10):1650-7.

[68] Wang SZ, Rui YF, Tan Q, Wang C. Enhancing intervertebral disc repair and regeneration through biology: platelet-rich plasma as an alternative strategy. Arthritis Res Ther. 2013;15(5):220.

[69] Chang KV, Hung CY, Aliwarga F, Wang TG, Han DS, Chen WS.Comparative effectiveness of platelet-rich plasma injections for treating knee joint cartilage degenerative pathology: a systematic review and meta-analysis. Arch Phys Med Rehabil. 2014 Mar;95(3):562-75.

[70] Khoshbin A(1), Leroux T, Wasserstein D, Marks P, Theodoropoulos J, Ogilvie-HarrisD, Gandhi R, Takhar K, Lum G, Chahal J. The efficacy of platelet-rich plasma in the treatment of symptomatic knee osteoarthritis: a systematic review with quantitative synthesis. Arthroscopy. 2013 Dec;29(12):2037-48

[71] [71] Sánchez M1, Guadilla J, Fiz N, Andia I. Ultrasound-guided platelet-rich plasma injections for the treatment of osteoarthritis of the hip. Rheumatology (Oxford). 2012 Jan;51(1):144-50.

[72] Chahal J, Van Thiel GS, Mall N, Heard W, Bach BR, Cole BJ, Nicholson GP, Verma $\mathrm{NN}$, Whelan DB, Romeo AA.The role of platelet-rich plasma in arthroscopic rotator cuff repair: a systematic review with quantitative synthesis. Arthroscopy. 2012 Nov; 28(11):1718-27

[73] Ahmad Z, Brooks R, Kang SN, Weaver H, Nunney I, Tytherleigh-Strong G, Rushton $\mathrm{N}$. The effect of platelet-rich plasma on clinical outcomes in lateral epicondylitis. Arthroscopy. 2013 Nov;29(11):1851-62

[74] A Hamid MS, Mohamed Ali MR, Yusof A, George J, Lee LP. Platelet-Rich Plasma Injections for the Treatment of Hamstring Injuries: A Randomized Controlled Trial. Am J Sports Med. 2014 Jul 29. pii: 0363546514541540

[75] Reurink G, Goudswaard GT, Moen MH, Weir A, Verhaar JAN, Maas M, Tol JL. Platelet rich plasma injections in acute muscle injury. N Engl J Med 2014; 370(26): 2546-2547

[76] Paques M, Chastang C, Mathis A, Sahel J, Massin P, Dosquet C, Korobelnik JF, Le Gargasson JF, Gaudric A. Effect of autologous platelet concentrate in surgery for idiopathic macular hole: results of a multicenter, double-masked, randomized trial. Platelets in Macular Hole Surgery Group. Ophthalmology. 1999;106(5):932-8

[77] Pan Q1, Angelina A, Zambrano A, Marrone M, Stark WJ, Heflin T, Tang L, Akpek EK. Autologous serum eye drops for dry eye. Cochrane Database Syst Rev. 2013 Aug 27;8:CD009327. doi: 10.1002/14651858.CD009327.pub2. 
[78] Avila MY. Restoration of human lacrimal function following platelet-rich plasma injection. Cornea. 2014 Jan;33(1):18-21

[79] Javaloy J, Alió JL, Rodriguez AE, Vega A, Muñoz G. Effect of platelet-rich plasma in nerve regeneration after LASIK. J Refract Surg. 2013 Mar;29(3):213-9.

[80] Alio JL, Rodriguez AE, Martinez LM, Rio AL. Autologous fibrin membrane combined with solid platelet-rich plasma in the management of perforated corneal ulcers: a pilot study. JAMA Ophthalmol. 2013 Jun;131(6):745-51

[81] Kim KM, Shin YT, Kim HK. Effect of autologous platelet-rich plasma on persistent corneal epithelial defect after infectious keratitis. Jpn J Ophthalmol. 2012 Nov;56(6): 544-50

[82] Anitua E, Muruzabal F, Alcalde I, Merayo-Lloves J, Orive G. Plasma rich in growth factors (PRGF-Endoret) stimulates corneal wound healing and reduces haze formation after PRK surgery. Exp Eye Res. 2013 Oct;115:153-61.

[83] Pezzotta S1, Del Fante C, Scudeller L, Cervio M, Antoniazzi ER, Perotti C Autologous platelet lysate for treatment of refractory ocular GVHD. Bone Marrow Transplant. 2012;47(12):1558-63

[84] Shirvan MK, Alamdari DH, Ghoreifi A. A novel method for iatrogenic vesicovaginal fistula treatment: autologous platelet rich plasma injection and platelet rich fibrin glue interposition. J Urol. 2013;189(6):2125-9

[85] Lee HJ, Kwon SH, Choi JW, Park KC, Youn SW, Huh CH, Na JI. The management of infantile extravasation injury using maternal platelet-rich plasma. Pediatr Dermatol. 2013;30(6):e114-7.

[86] Einarsson JI, Jonsdottir K, Mandle R. Use of autologous platelet gel in female pelvic organ prolapse surgery: a feasibility study. J Minim Invasive Gynecol. 2009 Mar-Apr; 16(2):204-7.

[87] Gorlero F, Glorio M, Lorenzi P, Bruno-Franco M, Mazzei C. New approach in vaginal prolapse repair: mini-invasive surgery associated with application of platelet-rich fibrin. Int Urogynecol J. 2012 Jun;23(6):715-22. 
